\title{
BORDETELLA PERTUSSIS MPLA AND RIBOFLAVIN AS ADJUVANTS FOR TRIVALENT INFLUENZA VACCINE
}

Wagner Quintilio, Fábio Alessandro de Freitas, Cosue Miyaki and Isaias Raw

Instituto Butantan, São Paulo, Brasil.

*Correspondling Author: Wagner Quintilio, Instituto Butantan, São Paulo, Brasil. Email: wagner.quintilio@butantan.gov.br Tel: +55 $112627-9450$

Citation: Wagner Quintilio (2017). BORDETELLA PERTUSSIS MPLA AND RIBOFLAVIN AS ADJUVANTS FOR TRIVALENT INFLUENZA VACCINE Int J Vac \& Im Sys. 2:1 7-12

Copyright: (C) 2017 Wagner Quintilio. This is an open-access article distributed under the terms of the Creative Commons Attribution License, which permits unrestricted use, distribution, and reproduction in any medium, provided the original author and source are credited.

Received January 102017 Accepted January 12 2017; Published February 102017

\section{Abstract:}

Adjuvanted trivalent influenza vaccines containing $3.75 \mu \mathrm{g}$ of each antigen strain with alum and riboflavin or Bordetella pertussis MPLA were tested in mice. Immune response was evaluated by haemagglutination inhibition test, ELISA and antibody affinity test. The highest increase in antibody titers was obtained with the formulation containing MPLA. Significant increase in HAI titer was observed when mice received the formulation containing MPLA and alum, with a clear cross reaction between B lineages. Corroborating our previous results with monovalent vaccine, this study confirmed the adjuvant formulations containing MPLA or Riboflavin as promising adjuvants to be evaluated in clinical trials.

Keywords: Influenza vaccine, adjuvants, vitamins, MPLA, TIV, QIV.

\section{I.INTRODUCTION}

Seasonal influenza vaccines are usually composed by antigen, i.e., split virus, in a physiological buffer containing or not conservatives. The use of adjuvanted vaccines with reduced antigen amount in humans have already showed efficacy in a monovalent formulation (Precioso et al, 2011) and could be an important tool for antigensparing, for reducing costs or to increase the immune response to new pandemic strains, taking in account the use of an affordable adjuvant.

At the same time, since 2013, WHO has been recommended the use of quadrivalent influenza vaccines containing two strains of type B lineages (Yamagata and Victoria) once both lineages have been co-circulating (WHO). However, this increase in vaccine cost might be a trouble in low income and developing countries either financial and product availability. A formulation that could elicit cross-reacting antibodies to B lineages would be especially useful to solve this situation.

In light of these facts and considering previous results for monovalent A/H1N1 vaccine (Quintilio et al, 2016; Precioso et al, 2011), in this paper we describe the effect of MPLA and riboflavin combined to alum as adjuvant as a proof-of-concept for trivalent influenza vaccine. The effect of the formulations on eliciting antibody titers and on cross reactivity between B strains (Yamagata and Victoria) were evaluated in order to elucidate the choice for better candidate vaccine adjuvant.

\section{Materials and Methods}

Animals

All animal tests were performed following the guidelines from Instituto Butantan Animal Care and Use Committee (permit CEUA 3096300915).

Female BALB/c mice (Mus muscullus) aged 6-8 weeks were provided by Instituto Butantan Animal Facilities. During the experiments they received balanced food and fresh water ad libitum.

Guinea pigs (Cavia porcellus) red blood cells suspension at $1 \%$ was provided by Influenza Laboratory.

\section{Reagents}

Riboflavin (Vitamin B2) was purchased from Merck. MPLA 
(Bordetella pertussis Monophosphoryl Lipid A) was produced at Instituto Butantan as a by-product of pertussis-low vaccine production [Quintilio et al., 2009]. Alum (Alhydrogel ${ }^{\circledR}$ - Brenntag Biosector) is a sterilized aluminum hydroxide gel suspension, which quantity is expressed in $\mathrm{mg}$ of $\mathrm{Al} 3+$. IgG anti-mousehorsehadish peroxidaseconjugate for ELISA was purchased from Sigma-Aldrich. Influenza antigen A/California/7/2009 (H1N1) pdm09，A/Texas/50/2012，B/Massachusetts/2/2012 (Yamagata lineage) and B/Brisbane/60/2008 (Victoria lineage) - purified split influenza vaccine grown in eggs, formaldehyde inactivated - were produced and kindly provided by Influenza Laboratory at Instituto Butantan.

\section{Immunization and bleeding}

Mice were immunized intraperitoneally $(0.5 \mathrm{~mL})$ with trivalent influenza vaccine $(3.75 \mu \mathrm{g}$ of each antigen strain, considering 2014 Southern hemisphere composition) with or without adjuvant (32.5 $\mu \mathrm{g}$ of riboflavin with $0.25 \mathrm{mg}$ of alum or $5 \mu \mathrm{g}$ of MPLA with $0.25 \mathrm{mg}$ of alum/dose). At 21, 60 and 67 days after immunization, individual serum was obtained by submandibular bleeding and was kept at $20^{\circ} \mathrm{C}$ until antibodies quantification tests. In order to evaluate immunological memory response, at day 60 the mice received a booster containing 1/10th of the first dose of trivalent vaccine without adjuvant.

\section{Antibodies quantification}

Haemagglutination Inhibition test (HAI) was performed individually by using guinea-pigs red blood cells suspension at $1 \%$. Titers were reported as the reciprocal of the highest sera dilution that completely inhibits haemagglutination. HAI titer $\geq 40$ is considered a correlate of protection in humans [EMEA, 2015].

ELISAs to determine antibodies titers against each antigen separately were performed as described previously (Quintilio et al, 2016). Two fold dilutions of individual sera were incubated in ELISA 96 wells polystyrene plates (Costar) coated with antigen at $1 \mu \mathrm{g} / \mathrm{mL}$. HRP anti-mouse IgG conjugate was used to detect IgG titers with $3,3^{\prime}, 5,5^{\prime}$-tetramethylbenzidine as substrate. Antibody titers were calculated by sigmoidal curve model (Combistats $\odot$ EDQM) by comparison to the unadjuvanted vaccine at day 21, which titer was arbitrarily considered 1.

For affinity ELISA measurements, the assays were performed as described above, but including a potassium thiocyanate (KSCN; 0 to $10 \mathrm{M}$, dilution factor 1.5) step as described (Guidolin et al, 2013) after the serum incubation (dilution 1/400). The results are expressed as affinity index (AI): KSCN concentration (mol/L) needed to displace $50 \%$ of the bound antibodies.

Each vaccine strain was tested separately including the B Victoria strain in order to check cross reactivity. All graphs were prepared by using GraphPad Prism ${ }^{\circledR} 5.01$ for MS-Windows ${ }^{\mathrm{TM}}$.

Statistical analysis was performed by using GraphPad Prism ${ }^{\circledR}$ 5.01. Kruskal-Wallis and Dunns' multiple comparison tests were applied $(\mathrm{p}<0.05)$.

\section{Results}

Based on the previous results, the formulations containing MPLA, riboflavin and alum were evaluated in order to characterize the immunological response against the $\mathrm{A} / \mathrm{H} 1 \mathrm{~N} 1, \mathrm{~A} / \mathrm{H} 3 \mathrm{~N} 2$ and $\mathrm{B} /$ Yamagata influenza antigen in a trivalent vaccine. Besides to the cross reactivity against B/Victoria lineage individual HAI and antibody titration by ELISA (IgG) and affinity induced by the vaccine formulations were evaluated.

Individual HAI results corroborated the previous experiments (Quintilio et al, 2016). Adjuvanted formulations induced higher antibody titers than the unadjuvanted vaccine for all strains (Fig. 1). There were no significant differences between formulations after booster. However, before the booster, for A strains, especially, the use of adjuvants elicited higher HAI titers. When the cross-reactivity between B lineages was evaluated, 21 days after immunization, only MPLA with alum induced mean titer $1 / 40$, the other two groups elicited lower antibodies titer (Fig. 1). Nevertheless, the HAI titer increased during time and after booster there was a significant difference between MPLA+alum group and unadjuvanted vaccine. 


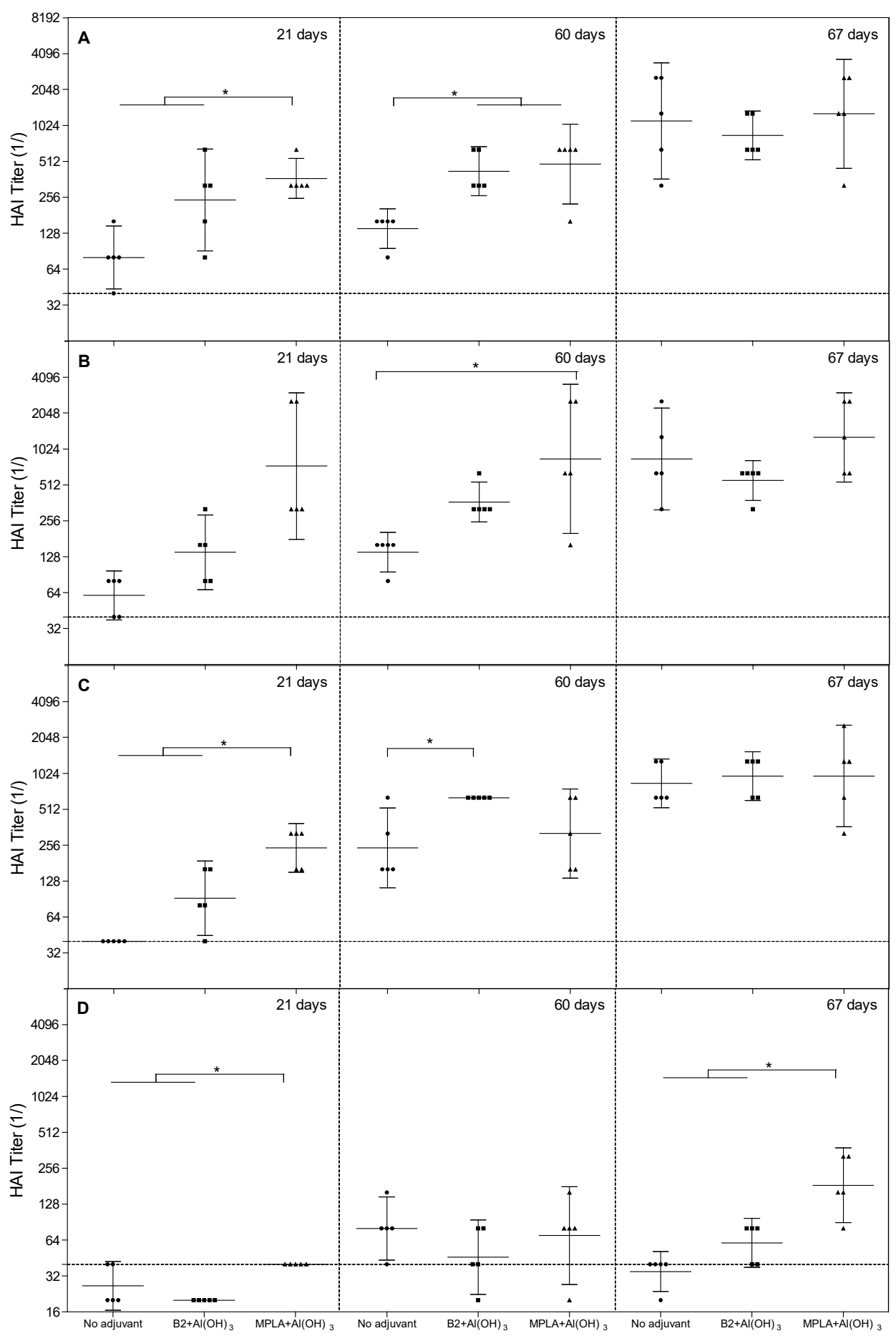

Figure 1. HAI GMT (the error bars indicate 95\% confidence interval): (A) A/H1N1; (B) A/H3N2; (C) B/ Yamagata; (D) B/Victoria. Mice received the trivalent influenza vaccines at day 0 (initial) and a booster $(0.375 \mu \mathrm{g}$ of each antigen) at day 60 . They were bled and the sera were titred with guinea-pig red blood cells at 21, 60 and 67 days after initial immunization. Dotted line indicates the minimum protective titer. * indicates statistically significant differences among groups. 
Reflecting these HAI results, IgG titer indicated that formulation containing alum+MPLA induced higher titers after booster against all strains. Despite the positive response against B/Victoria lineage, IgG titers were significantly lower than those observed against B/ Yamagata (Fig. 2).
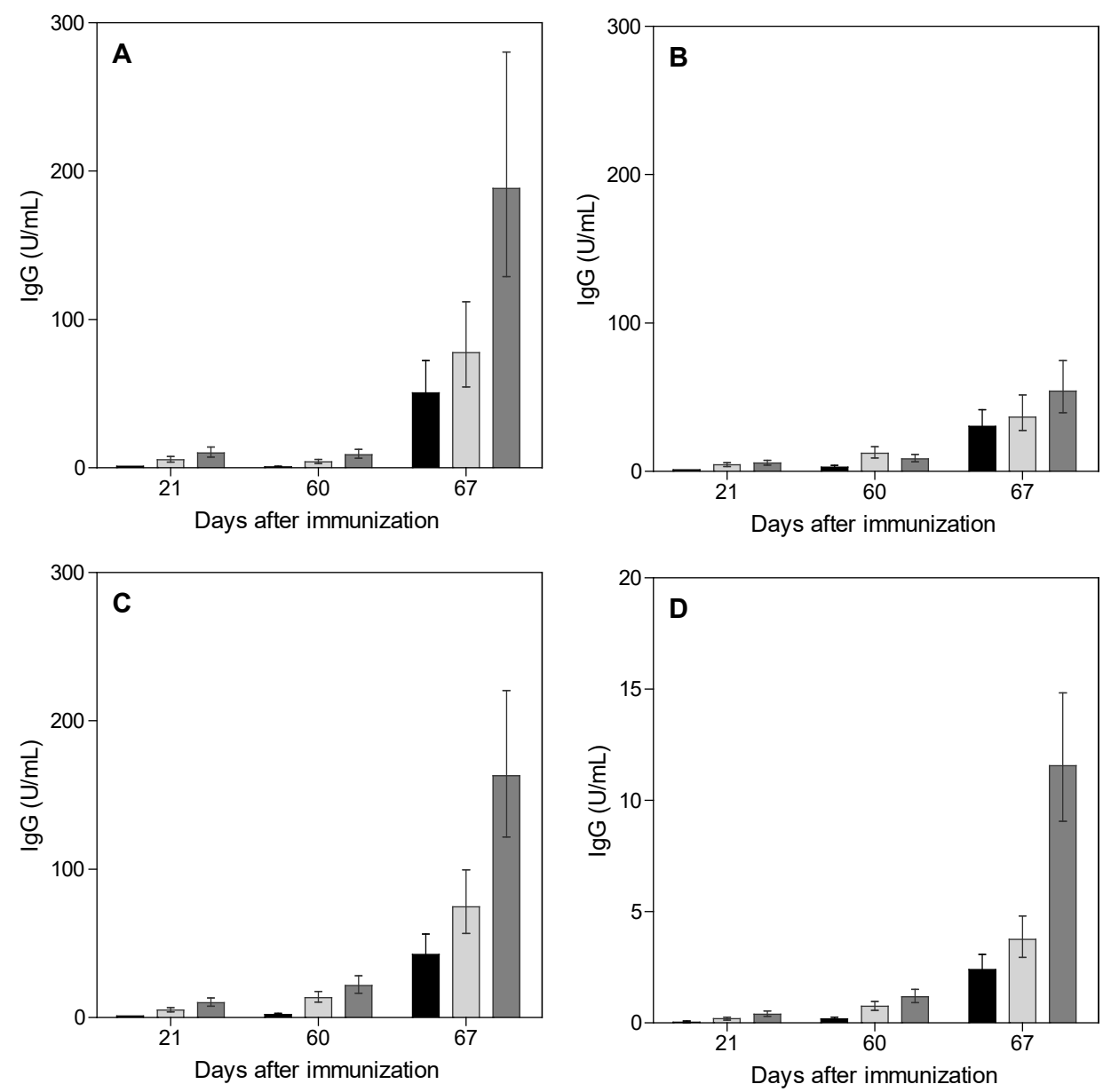

Figure 2. GMT IgG in mice sera. Mice received non-adjuvanted vaccine ( $\square$ ), vaccine containing riboflavin and alum $(\square)$ and vaccine containing MPLA with alum $(\square)$ at day 0 and were bled at 21, 60 and 67 days after immunization. (A) anti-H1N1, (B) anti-H3N2, (C) anti-B/Yamagata, (D) anti-B/Victoria. At day 60 all animals received unadjuvanted $0.375 \mu \mathrm{g}$ of each antigen as booster. Error bar represents $95 \%$ confidence interval. 
In order to check if the increased titers were related to higher antibody affinities, an affinity ELISA was performed. After booster, all groups presented an increased affinity. However, when animals received vaccines with alum and MPLA the affinity index increasing was remarkable (Table 1). Riboflavin with alum presented an adjuvant effect more evident for A strains, but MPLA with alum was more effective in all cases.

Table 1. Affinity index before and after the booster (pooled sera).

\begin{tabular}{|c|c|c|c|}
\hline \multirow[b]{2}{*}{ Adjuvant/strain } & \multicolumn{3}{|c|}{ Affinity index (M KSCN) } \\
\hline & $\begin{array}{c}\text { Before booster } \\
\text { (60 days after immuni- } \\
\text { zation) }\end{array}$ & $\begin{array}{c}\text { After Booster } \\
\text { (67 days after immu- } \\
\text { nization) }\end{array}$ & Variation $(\%)$ \\
\hline \multicolumn{4}{|r|}{$\mathrm{A} / \mathrm{H} 1 \mathrm{~N} 1$} \\
\hline No adjuvant & 1.143 & 2.359 & 106 \\
\hline $\mathrm{B} 2+\mathrm{Al}(\mathrm{OH})_{3}$ & 2.078 & 4.362 & 110 \\
\hline $\mathrm{MPLA}+\mathrm{Al}(\mathrm{OH})_{3}$ & 2.086 & 5.759 & 176 \\
\hline \multicolumn{4}{|r|}{$\mathrm{A} / \mathrm{H} 3 \mathrm{~N} 2$} \\
\hline No adjuvant & 1.167 & 1.625 & 39 \\
\hline $\mathrm{B} 2+\mathrm{Al}(\mathrm{OH})_{3}$ & 1.568 & 2.416 & 54 \\
\hline $\mathrm{MPLA}+\mathrm{Al}(\mathrm{OH})_{3}$ & 1.63 & 3.374 & 107 \\
\hline \multicolumn{4}{|r|}{ B/Yamagata } \\
\hline No adjuvant & 0.5769 & 1.092 & 89 \\
\hline $\mathrm{B} 2+\mathrm{Al}(\mathrm{OH})_{3}$ & 1.036 & 1.786 & 72 \\
\hline $\mathrm{MPLA}+\mathrm{Al}(\mathrm{OH})_{3}$ & 0.9802 & 2.358 & 141 \\
\hline \multicolumn{4}{|r|}{ B/Victoria } \\
\hline No adjuvant & 0.8924 & 2.035 & 128 \\
\hline $\mathrm{B} 2+\mathrm{Al}(\mathrm{OH})_{3}$ & 1.699 & 2.449 & 44 \\
\hline $\mathrm{MPLA}+\mathrm{Al}(\mathrm{OH})_{3}$ & 1.54 & 7.311 & 375 \\
\hline
\end{tabular}

Affinity index as determined by ELISA using KSCN in elution step. B2=riboflvin

\section{Discussion}

It is important to emphasize that in this study the influenza vaccine contained $1 / 4$ th of the regular human dose. Meaning that by following this approach, there could be an important antigen spare, multiplying by 4 in theory the production plant capacity.

Previous published work (Quintilio et al, 2016) examinated the use of vitamins and MPLA as adjuvants for vaccines and at that moment, riboflavin with alum and MPLA with alum were the most promising adjuvants. Before trying with trivalent vaccine, one assay with monovalent $\mathrm{A} / \mathrm{H} 3 \mathrm{~N} 2$ and $\mathrm{B} /$ Yamagata strains was performed, confirming the results obtained for $\mathrm{A} / \mathrm{H} 1 \mathrm{~N} 1$ (data not shown). And the same profiles were observed also here with the trivalent vaccine. Except the affinity ELISA: the results were different from those obtained previously for adjuvanted monovalent H1N1 vaccine (Quintilio et al., 2016), likely due to the presence of other antigens, in our experimental model.

In the studied conditions MPLA with alum induced higher antibody titers than those obtained with riboflavin and alum. Further studies must be performed in order to characterize the effect of each adjuvant formulation.
Many studies have been pointed that the use of quadrivalent vaccines could reduce hospitalizations number and work absenteeism presenting therefore a good cost-effectiveness ratio (Gordon et al, 2016; Zerbini et al, 2016). At the same time it is known that by using adjuvant, cross-reactive antibodies have been observed in a clinical assay in humans (Camilloni et al, 2009). The results presented here indicate that MPLA with alum may elicit cross-protection, potentially mimicking a quadrivalent influenza vaccine containing though $1 / 4$ th of the antigen usually present in conventional vaccines.

In spite of the fact that a human is not a $70 \mathrm{~kg}$ mouse, these results are useful to steer the vaccine development and critical answers only a clinical trials in humans can bring.

\section{Conflict of interest}

None

\section{Author contributions}

WQ collected and analyzed data and wrote the manuscript; FAF and $\mathrm{CM}$ wrote the manuscript; IR idealized the project and wrote the manuscript. 


\section{Acknowledgments}

The authors would like to acknowledge Dr Celso Pereira Caricati for the kind and helpful support, DDTP for the MPLA supply. Maria Rosa Lange da Silva and Marisa de Souza Silva de Oliveira for the support in animal housing. Financial support by Fundação Butantan.

\section{REFERENCES}

1. B. Camilloni, M. Neri, E. Lepri, A.M. Iorio. Cross-reactive antibodies in middle-aged and elderly volunteers after MF59adjuvanted subunit trivalent influenza vaccine against $B$ viruses of the B/Victoria or B/Yamagata lineages. Vaccine, 27(31): 40994103. http://dx.doi.org/10.1016/j.vaccine.2009.04.078

2. David L. Gordon, Dimitar Sajkov, Yoshikazu Honda-Okubo, Samuel H. Wilks, f, Malet Aban, Ian G. Barr, Nikolai Petrovsky. Human Phase 1 trial of low-dose inactivated seasonal influenza vaccine formulated with Advax ${ }^{\mathrm{TM}}$ delta inulin adjuvant. Vaccine. Volume 34, Issue 33, 19 July 2016, Pages 3780-3786. http:// dx.doi.org/10.1016/j.vaccine.2016.05.071

3. EMEA. Committee for Proprietary Medicinal Products. Note for Guidance on Harmonisation of Requirements for Influenza Vaccines. London: European Medicines Agency, 1996. 18p. (Publication n.CPMP/BWP/214/96). http://www.ema.europa. eu/docs/en_GB/document_library/Scientific_guideline/2009/09/ WC500003945.pdf. Accessed 09 December 2016

4. Eun-Ju Ko, Young-Tae Lee, Ki-Hye Kim, Youri Lee, Yu-Jin Jung, Min-Chul Kim, Yu-Na Lee, Taeuk Kang, and Sang-Moo Kang. Roles of Aluminum Hydroxide and Monophosphoryl
5. Lipid A Adjuvants in Overcoming CD4+ T Cell Deficiency To Induce Isotype-Switched $\operatorname{IgG}$ Antibody Responses and Protection by T-Dependent Influenza Vaccine, J. Immunol. 2016 : jimmunol.1600173v1-1600173.

6. Guidolin FR, Tambourgi DV, Guidolin R, Marcelino JR, Okamoto CK et al (2013) Characterization of anti-crotalic antibodies. Toxicon. 66:7-17

7. Precioso AR, Miraglia JL, Campus LM, Gourlart AC, Timenetsky M do C, Cardoso, Luna E, Mondrini G, Guedes J da S, Raw I (2011) A phase I randomized double-bind controlled trial of 2009 influenza A (H1N1) inactivated monovalent vaccines with different adjuvants. Vaccine 29(48):8974-8981

8. Quintilio W, de Freitas FA, Rodriguez D, Kubrusly FS, Yourtov D, Miyaki C, de Cerqueira Leite LC, Raw I. Vitamins as influenza vaccine adjuvant components. Arch Virol. 2016 Oct;161(10):278795. doi: 10.1007/s00705-016-2994-5.

9. Quintilio W, Kubrusly FS, Iourtov D, Miyaki C, Sakauchi MA, Lúcio F, Dias S de C, Takata CS, Miyaji EN, Higashi HG, Leite LC, Raw I (2009) Bordetella pertussis monophosphoryl lipid A as adjuvant for inactived split virion influenza vaccine in mice. Vaccine 27(31):4219-4224

10. Zerbini CA, Santos RR, Nunes MJ, Soni J, Li P, Jain VK, OforiAnyinam O. Immunogenicity and safety of Southern Hemisphere quadrivalent inactivated influenza vaccine: a Phase III, open-label study of adults in Brazil. Braz J Infect Dis. 2016 Nov 29. pii: S1413-8670(16)30548-7. doi: 10.1016/j.bjid.2016.10.003. [Epub ahead of print] 